\title{
THE CLIMATE OF THE CANARY ISLANDS BY ANNUAL CYCLE PARAMETERS
}

\author{
B. Bechtel ${ }^{\text {a, * }}$ \\ ${ }^{a}$ University of Hamburg, Center for Earth System Research and Sustainability, Hamburg, Germany. \\ * benjamin.bechtel@uni-hamburg.de
}

Commission VIII, WG VIII/3

KEY WORDS: Land surface temperature, annual temperature cycle, thermal infrared, MODIS.

\begin{abstract}
:
Annual cycle parameters (ACP) provide a global climatology of annual land surface temperature (LST) based on daily $1 \mathrm{~km}$ MODIS observations. These are based on a simple model of the annual temperature cycle and allow estimating LST patterns under largely cloud-free conditions for every day of year. Further, they deliver measures for the LST variability and the frequency of cloud occurrence. It has been demonstrated, that they reproduce important surface climate characteristics at global and urban scale but their ability to reproduce topo-climates has yet to be studied in detail. In this paper their suitability to investigate climatic variability at $\mathrm{km}$ scale were studied at the case of the Canary Islands (Spain). This Archipelago, has a very stable climate dominated by the Azores high and the trade wind belt, but shows a large number of micro-climates ranging from arid hot climates to cold climates. It was found that ACPs are a relevant source of climatic information at km scale in complex orography. Specifically, known features such as subsidence inversion, the resulting sea of clouds, the strong differentiation in precipitation between the flat and high islands, as well as the northern and southern slopes at the latter were clearly visible in the parameters.
\end{abstract}

\section{INTRODUCTION}

The Canary Archipelago, west of Morocco consists of seven islands with a total area of about $7500 \mathrm{~km}^{2}$. While its climate is generally stable and dominated by the Azores high and the trade wind belt, it shows a large number of micro-climates ranging from hot desert climates to subtropical humid climates and frequent occurrence of snow on Mount Teide, the highest mountain of Spain. Additionally, the Canary Islands are facing an accelerating warming trend (Martin et al. 2012) and a strong decreasing precipitation trend in the second half of the $20^{\text {th }}$ century (García-Herrera et al., 2003) which is expected to have significant impacts on the diverse ecosystems as well as agriculture.

To study this diversity of climates spatially dense observations are needed. However, due to high maintenance costs, the number of in situ sensors for climate observation and monitoring is limited. To address the lack of this type of observational data, meso-scale numerical modelling can be used to study the small scale differences, but it is very sensitive to the choice of model parameters. Pérez et al. (2014) found the numerical model WRF to be especially sensitive to the used cumulus scheme and that different choices of parameterisation produced temperature differences in the same order of magnitude as the variability in sea surface temperature of $0.78 \mathrm{~K}$ as estimated from phase 5 of the Coupled Model Intercomparison Project (CMIP5).

Remote sensing potentially offers a means to extensively observe these various climates and thus close the information gap. However highly relevant meteorological parameters such as air temperature and precipitation cannot be observed directly and regular observations and their accuracy are limited by trade-offs between spectral, spatial and temporal resolutions, cloud coverage, and general atmospheric influences.
Thus, robust parameters, which are closely related to the most important climatic variables, are urgently needed.

Annual cycle parameters (ACP) provide a global climatology of annual land surface temperature (LST) based on daily $1 \mathrm{~km}$ MODIS observations (Bechtel, 2015). They are based on a simple model of the annual temperature cycle (Bechtel, 2012) and allow estimating LST patterns under largely cloud-free conditions for every day of year. Further, they deliver measures of the inter-diurnal and inter-annual surface temperature variability and the frequency of cloud occurrence. It has been demonstrated, that they reproduce important surface climate characteristics at global scales as well as urban climatic effects but their ability to reproduce topo-climates in complex orography has not been studied so far.

In this paper their suitability to investigate climatic variability at $\mathrm{km}$ scale is studied using the diversity of climates on the Canary Islands as an test case.

\section{DATA}

\subsection{Annual cycle Annual cycle parameters}

ACP are a simplified LST climatology during largely cloud free conditions at time of acquisition (Bechtel, 2015). They are generated from LST time series and divide each observation into a long-term average annual cycle of LST (controlled by irradiation and climatology) as well as a day-specific anomaly (controlled by meteorological, vegetation and soil conditions, and orbital parameters), hereafter referred to as residuals.

Since the climatology is periodic it can be approximated by a series of harmonic functions (Bechtel, 2012). The principal is illustrated in Figure 1. Instead of limiting the analysis to the comparably rare entirely cloud free scenes Figure 1a) shows examples form different seasons), the time series for each pixel are considered taking into account all available observations.

\footnotetext{
Corresponding author
} 


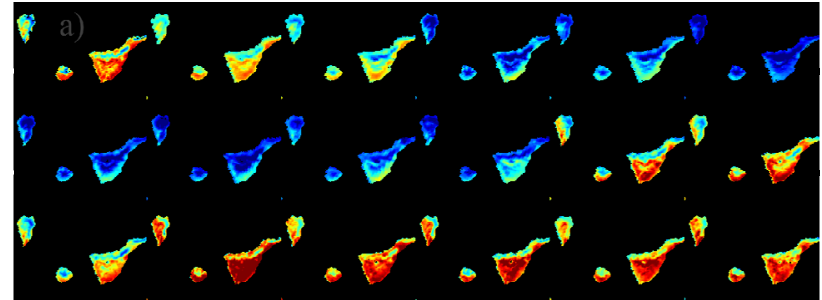

b)
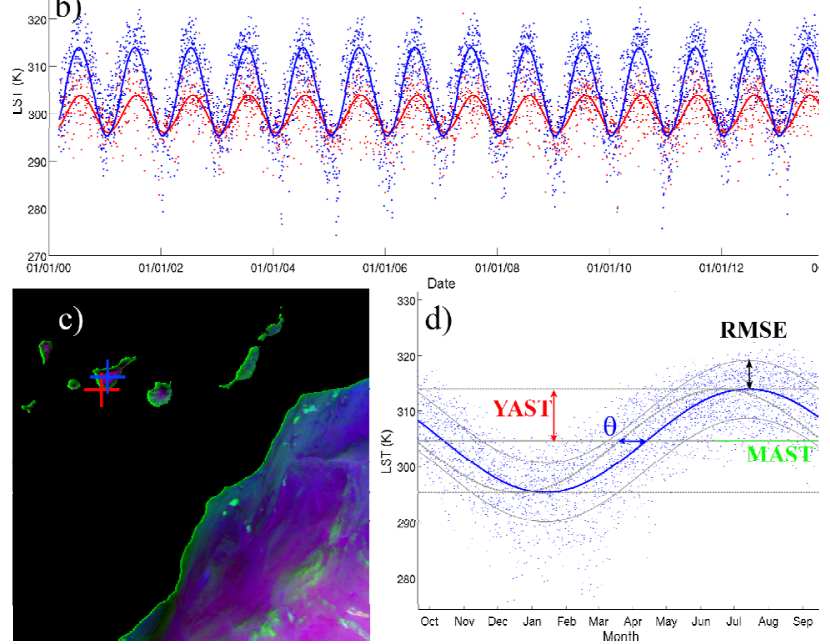

Figure 1. Principle of the annual cycle parameters. (a) Cloudfree acquisitions from the Canary Islands showing Tenerife, La Gomera and La Palma (subset of tile h16v16) from different seasons (and years). (b) Full time series for two selected pixels with different annual LST characteristics (blue: Pixel on Mount Teide, red: pixel in South Tenerife) 2000-2013. (c) color composite from the fitted parameters YAST, MAST and phase shift $\theta$ (RGB). Selected pixels are marked with +. (d) Annual cycle of the Mount Teide pixel and explanation of the parameters YAST, MAST, $\theta$, and RMSE.

Figure 1b) shows this time series for two pixels which exhibit a periodic annual variation (undulating wave form) and short term influence from other factors (individual points). The annual variation is explained by the ACP model (Figure 1d). The annual cycle is approximated by the following function:

$$
f(d)=M A S T+Y A S T \sin (d 2 \pi / 365+\theta)
$$

where

$$
\begin{aligned}
& d=\text { day of the cycle } \\
& \text { MAST = mean annual surface temperature }(\mathrm{K}) \\
& \text { YAST = yearly amplitude of surface temp. }(\mathrm{K}) \\
& \Theta=\text { phase shift (days after } 21 \text { st of March) }
\end{aligned}
$$

The phase shift expresses how much the peak in LST is delayed compared to the peak in the radiative forcing and thus is a measure of the latency of heat uptake. Since the Canary Islands are North of the Tropic of Cancer $\left(23^{\circ} 26^{\prime} \mathrm{N}\right)$ the approximation by a single periodic term is acceptable.

Additional the root mean squared error (RMSE) and the number of clear sky acquisitions/observations (NCSA/Nobs) are derived. The RMSE is the quadratic mean of the residuals and therefore an integrated measure of the inter-diurnal and interannual variability of LST. The NCSA on the other hand, are a measure for frequency of cloud occurrence, although it is influenced by orbital characteristics.
The ACPs for every pixel were estimated from the 12-year time series of MODIS LST measurements from (2003-2014) with an optimization algorithm minimizing the square sum of the residuals. The parameters were derived based on Version 5 of the MODIS daily level 3 global $1 \mathrm{~km}$ grid Land Surface Temperature and Emissivity product from EOS-Terra and Aqua (MOD11A1, MYD11A1) (Wan, 2007). This data is produced with a generalized split window approach using the MODIS bands 31 and 32 (Wan and Dozier, 1996), the emissivity is based on a classification based approach of (Snyder et al., 1998) for 18 land cover types with some small modifications (Wan, 2008). The accuracy of the LST product was found to mostly be within $1 \mathrm{~K}$ (Wan et al., 2004).Version 5 of the product contains a number of major refinements compared to the versions 4 and 4.1 (Wan, 2008), version 6 is currently produced but not fully available yet. The MOD11A1 products are delivered in a sinusoidal grid which is inherited by the ACP product. The ACPs were computed separately for night time and for day time, resulting in four sets of parameters per day, which are subsequently referred to as $01: 30,10: 30,13: 30$ and 22:30 according to the overpass time. More detailed information on the processing and the dataset can be found in (Bechtel, 2015). The entire dataset is available for download from http://icdc.zmaw.de/daten/land/modis-lst-annualcycle.html.

\subsection{Digital Elevation Model}

The Shuttle Radar Topography Mission (SRTM) was flown aboard the Endeavour space shuttle in 2000 by the National Aeronautics and Space Administration (NASA) and the National Geospatial-Intelligence Agency (NGA). It is based on interferometric radar, comparing the phase shift in radar images from two radar antennas (one inside the space shuttle one antenna located at the end of a 60 -meter mast). Here the 1 ArcSecond Global product (SRTMGL1) was used, which is void filled using elevation data from ASTER GDEM2 and USGS GMTED 2010 and was recently extended to Europe, Asia and Africa. For more information see the SRTM User Guide (NASA, 2015). The band interleaved by line binary raster format was downloaded from the USGS EarthExplorer Website, reprojected to the MODIS sinusoidal grid, and resampled to the ACP resolution. A small offset of 1-2 pixels was found between the datasets but was considered tolerable for the given analysis.

\section{CANARY ISLANDS AND THEIR CLIMATE}

\subsection{Study area}

The Canary Archipelago is situated in the Atlantic Ocean west of the North African coast at the latitude of Morocco (approximately $18-13^{\circ} \mathrm{W}, 27-29^{\circ} \mathrm{N}$ ). It consists of seven islands, namely El Hierro, La Palma, La Gomera, Tenerife, Gran Canaria, Fuerteventura and Lanzarote (from west to east). The total area sums up to about $7500 \mathrm{~km}^{2}$. Figure 2a) shows a satellite image of the Archipelago. The islands are of volcanic origin, which leads to a high vertical range varying according to their age. The highest point is Mount Teide $(3718 \mathrm{~m})$ on Tenerife, which is also the highest mountain of Spain. With Tenerife being by far the highest island, La Palma, Gran Canaria, La Gomera and El Hierro constitute a medium cluster with the highest peaks of $2423 \mathrm{~m}$ (La Palma, Roque de los Muchachos $=$ rook of boys), $1948 \mathrm{~m}$ (Gran Canaria, Pico de Las Nieves), $1501 \mathrm{~m}$ (El Hierro, Pico de Malpaso = difficult step peak) and $1487 \mathrm{~m}$ (La Gomera, Garajonay). 


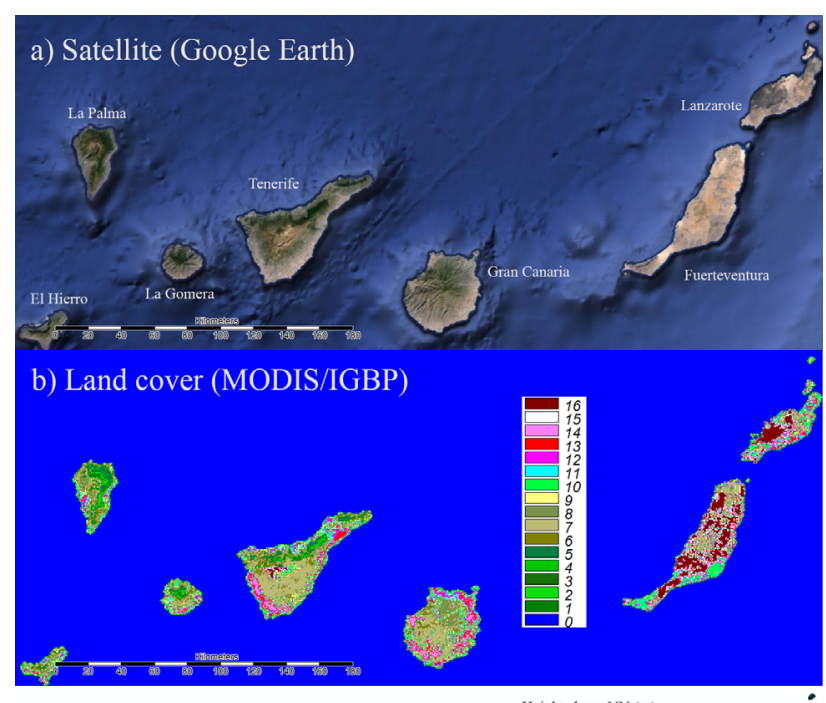

c) Elevation (SRTM)

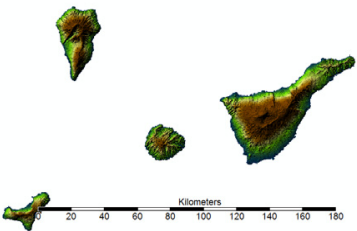

d) Elevation Class
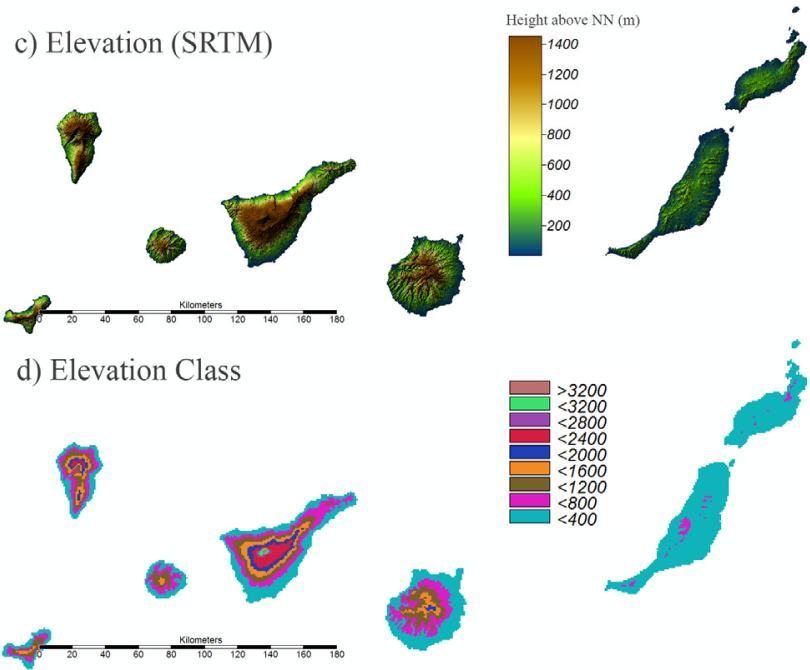

Figure 2. a) Satellite image (Google Earth); b) Land cover from MODIS (MCD12Q19), classes: 0: Water, 1: Evergreen Needleleaf forest, 2: Evergreen Broadleaf forest, 3: Deciduous Needleleaf forest, 4: Deciduous Broadleaf forest, 5: Mixed forest, 6: Closed shrublands, 7: Open shrublands, 8: Woody savannas, 9: Savannas, 10: Grasslands, 11: Permanent wetlands, 12: Croplands, 13: Urban and built-up, 14: Cropland/Natural vegetation mosaic, 15: Snow and ice, 16: Barren or sparsely vegetated (IBGP); c) Elevation asl from SRTM in m; d) Elevation class in $400 \mathrm{~m}$ intervals.

Lanzarote and Fuerteventura on the other hand are much flatter with maximum heights of $671 \mathrm{~m}$ and $807 \mathrm{~m}$ respectively. An elevation map based on SRTM is presented in Figure 2c). Since different authors employed $400 \mathrm{~m}$ intervals for stratifying elevation (Luque et al., 2013; Martín et al., 2012) the same was applied in this study. The respective elevation classes are given in Figure 2d). The different altitudes and resulting climatic conditions (see next section) produce a variety of different ecosystems and land covers which are illustrated by the IBGP land cover classes in Figure 2b).

\subsection{Climate of Canary Islands}

The climate of the Canary Islands is generally very stable and dry (Pérez et al., 2014) due to the influence of the trade wind
Belt and the Azores high although it is influenced by the North Atlantic Oscillation (Herrera et al., 2001). The vertical stratification shows a typical structure with three layers (Herrera et al., 2001). The low levels up to about $700 \mathrm{~m}$ hold cold and moist air resulting from cold surface water of the Canaries Current. Above a subsidence inversion is found up to about $1500 \mathrm{~m}$, resulting from the downwelling flow of the Hadley cell. The temperature increase throughout this layer effectively prevents any convection and accordingly transport of water vapor in higher altitudes. Consequently, water vapor is condensed below the inversion layer resulting in thin stratocumulus clouds (typically nonprecipitating), which are called "sea of clouds" (Herrera et al., 2001). Rainfall only occurs when this stable inversion layer is broken by disturbances (Herrera et al., 2001). However, the stratification is seasonally changing (Marzol, 2008). Luque et al. (2013) for instance state for Gran Canaria that the cloud layer typically lies between 1200 and $1600 \mathrm{~m}$ but often descends to 800$1000 \mathrm{~m}$ in July and August. Further the vertical stratification can vanish under hot air invasions during dust outbreak events from the Sahara (Luque et al., 2013), which are called Calima on the Canary Islands. These intrusions are most frequent in Winter and least in Spring and lead to a temperature increase and decrease in hygrometric values, wind mainly from the East, stable atmosphere and decreased visibility due to airborne dust (Dorta-Antequera et al., n.d.).

Due to the high vertical range and the resulting differences in temperature and precipitation the Archipelago shows a large number of different climates. A widely used discretisation for such climates is the Köppen Scheme, originally proposed by Wladimir Köppen in 1900. It considers average monthly precipitation and temperature based on climate normals and specific thresholds, which are critical for their influence on vegetation. Figure 3a) shows the Köppen Climate Classification of the Canary Islands from the Climate Atlas of the Spanish Met service (AEMET, 2012). This Atlas used meteorological observations to record meteorological conditions and to classify the respective climates and employed the recently updated version of the Köppen classification by Peel et al. (2007). It can be seen that the Canary Islands are largely comprised of arid (B) and temperate (C) climates, but even cold (D) climates occur on the peak of Mount Teide, which corresponds to a distance of many thousand $\mathrm{km}$ in latitude. A summary of the classes, the thresholds, and their occurrence on the Canary Islands are given in Table 1.

Figure 3 additionally shows the average temperature and precipitation from the atlas, based on meteorological observations for the climatological normal period from 19712000). The air temperature pattern was generated using multiple linear regression with altitude, latitude and longitude as predictors and the residuals were interpolated by inverse distance weighting. For precipitation this was hampered by the complexity of the spatial distribution with maximum precipitation occurring at intermediate altitudes, at the north and northeast facing slopes. Thus, universal Kriging with altitude as covariate was applied with satisfactory results due to the high number of rain gauges (AEMET, 2012), although only Gran Canaria and Teneriffe have dense meteorological station networks (Luque et al., 2013). The temperature distribution is clearly determined by the elevation. The precipitation is controlled by both the altitude and the orientation towards the dominant wind direction where the trade winds advect moist air masses, which lead to orographic condensation and subsequent precipitation when rising over the island slopes (Herrera et al., 2001) resulting in higher rainfall in the North and North-Eastern parts of the higher islands. Oppositely, Lanzarote and 
Fuerteventura hardly get any precipitation at all due to their low vertical extend, which is corresponding with their arid (B) climates. While the northern parts of the high islands have precipitation amounts around $1000 \mathrm{~mm}$ per year, the southern parts of these islands and the flatter islands (Lanzarote and Fuerteventura) receive mean precipitation amounts of about $200 \mathrm{~mm}$ per year (AEMET, 2012; Pérez et al., 2014).

\begin{tabular}{|c|c|c|c|c|c|}
\hline $1 \mathrm{st}$ & $t$ 2nd & 3rd & Description & Criteria & Occurence on Canary Islands \\
\hline \multirow[t]{4}{*}{$\mathbf{A}$} & & & Tropical & $\mathrm{T}_{\text {cold }} \geq 18$ & \\
\hline & f & & - Rainforest & $\mathrm{P}_{\mathrm{dry}} \geq 60$ & \\
\hline & $\mathrm{m}$ & & - Monsoon & $\begin{array}{l}\text { Not (Af) \& } \\
P_{\text {dry }} \geq 100-M A P / 25\end{array}$ & \\
\hline & $\mathrm{w}$ & & - Savannah & $\begin{array}{l}\text { Not (Af) \& } \\
P_{\text {dry }}<100-\text { MAP } / 25\end{array}$ & \\
\hline \multirow[t]{5}{*}{ B } & & & Arid & $\mathrm{MAP}<10 \times \mathrm{P}_{\text {threshold }}$ & \\
\hline & W & & - Desert & $\mathrm{MAP}<5 \times \mathrm{P}_{\text {threshold }}$ & \\
\hline & S & & - Steppe & $\mathrm{MAP} \geq 5 \times \mathrm{P}_{\text {threshold }}$ & $\begin{array}{l}\text { BSh \& BSk Both in all island incrasing } \\
\text { with altitude. Fuerteventura \& Lanzarote } \\
\text { (only in highest areas), Gran Canaria } \\
\text { (medium-low in N to high altitudes in S) } \\
\text { Tenerife, La Gomera \& El Hierro (asl in N } \\
\text { \& E) }\end{array}$ \\
\hline & & $\mathrm{h}$ & - Hot & MAT $\geq 18$ & $\begin{array}{l}\text { BWh Lanzarote \& Fuerteventura } \\
\text { (prdominant, except higher areas), Gran } \\
\text { Canaria, Tenerife \& La Gomera (south) El } \\
\text { Hierro (low-lying areas) }\end{array}$ \\
\hline & & k & - Cold & MAT $<18$ & $\begin{array}{l}\text { BWk Tenerife \& La Gomera (between } \\
\text { 500-700m altitude) }\end{array}$ \\
\hline \multirow[t]{7}{*}{ C } & & & Temperate & $\begin{array}{l}\mathrm{T}_{\text {hot }}>10 \& \\
0<\mathrm{T}_{\text {cold }}<18\end{array}$ & \\
\hline & $\mathrm{s}$ & & - Dry Summer & $\begin{array}{l}\mathrm{P}_{\text {sdry }}<40 \text { \& } \\
\mathrm{P}_{\text {sdry }}<\mathrm{P}_{\text {wwet }} / 3\end{array}$ & \\
\hline & w & & - Dry Winter & $\mathrm{P}_{\mathrm{wdry}}<\mathrm{P}_{\text {swet }} / 10$ & not observed \\
\hline & f & & $\begin{array}{l}\text { - Without dry } \\
\text { season }\end{array}$ & otherwise & not observed \\
\hline & & a & - Hot Summer & $\mathrm{T}_{\text {hot }} \geq 22$ & $\begin{array}{l}\text { Csa La Palma (coastal areas N \& E), } \\
\text { Gran Canaria, Tenerife \& La Gomera } \\
\text { (higher elevations) }\end{array}$ \\
\hline & & $\mathrm{b}$ & - Warm Summer & $\begin{array}{l}\text { Not (a) \& } \\
\mathrm{T}_{\text {monl } 10} \geq 4\end{array}$ & $\begin{array}{l}\text { Csb La Palma, El Hierro, La Gomera \& } \\
\text { Tenerife (widely through the interior), Gran } \\
\text { Canaria (higher areas) }\end{array}$ \\
\hline & & $\mathrm{c}$ & - Cold summer & $\begin{array}{l}\text { Not }(\mathrm{a} \text { or } \mathrm{b}) \& \\
1 \leq \mathrm{T}_{\operatorname{mon} 10}<4\end{array}$ & Csc Pico de Teide (2600-2900 m altitude) \\
\hline \multirow[t]{8}{*}{ D } & & & Cold & $\mathrm{T}_{\text {hot }}>10 \& \mathrm{~T}_{\text {cold }} \leq 0$ & \\
\hline & s & & - Dry Summer & $\begin{array}{l}\mathrm{P}_{\text {sdry }}<40 \& \& \\
\mathrm{P}_{\text {sdry }}<\mathrm{P}_{\text {wwet }} / 3\end{array}$ & \\
\hline & w & & - Dry Winter & $\mathrm{P}_{\mathrm{wdry}}<\mathrm{P}_{\text {swet }} / 10$ & \\
\hline & $\mathrm{f}$ & & $\begin{array}{l}\text { - Without dry } \\
\text { season }\end{array}$ & otherwise & $\begin{array}{l}\text { Dfc Tenerife ( } 2900 \mathrm{~m} \text { - top of Pico de } \\
\text { Teide) }\end{array}$ \\
\hline & & a & - Hot Summer & Thot $\geq 22$ & \\
\hline & & b & - Warm Summer & $\begin{array}{l}\text { Not (a) \& } \\
T_{\text {mon } 10 \geq 4}\end{array}$ & \\
\hline & & c & - Cold Summer & $\operatorname{Not}(a, b$ ord $d)$ & \\
\hline & & d & - Very Cold & $\begin{array}{l}\text { Not (a or b) \& } \\
T_{\text {cold }}<-38\end{array}$ & \\
\hline \multirow[t]{3}{*}{ E } & & & Polar & $\mathrm{T}_{\text {hot }}<10$ & \\
\hline & $\mathrm{T}$ & & - Tundra & $\mathrm{T}_{\text {hot }}>0$ & not observed \\
\hline & $\mathrm{F}$ & & - Frost & $\mathrm{T}_{\text {hot }} \leq 0$ & not observed \\
\hline
\end{tabular}

Table 1. Köppen Climates on the Canary Islands, combined from (AEMET, 2012; Peel et al., 2007). MAP mean annual precipitation, MAT - mean annual temperature, $\mathrm{T}_{\text {hot }}$ - temperature $(\mathrm{T})$ of the hottest month, $\mathrm{T}_{\text {cold }}-\mathrm{T}$ of the coldest month, $\mathrm{T}_{\text {mon10 }}-$ number of months where the $\mathrm{T}$ is above $10, \mathrm{P}_{\mathrm{dry}}-$ precipitation $(\mathrm{P})$ of the driest month, $\mathrm{P}_{\text {sdry }}-\mathrm{P}$ of the driest month in summer, $\mathrm{P}_{\mathrm{wdry}}-\mathrm{P}$ of the driest month in winter, $\mathrm{P}_{\text {swet }}-\mathrm{P}$ of the wettest month in summer, $\mathrm{P}_{\text {wwet }}-\mathrm{P}$ of the wettest month in winter, $\mathrm{P}_{\text {threshold }}$ - varies according to the following rules (if $70 \%$ of MAP occurs in winter: $P_{\text {threshold }}=2 \times$ MAT, if $70 \%$ of MAP occurs in summer: $\mathrm{P}_{\text {threshold }}=2 \times$ MAT +28 , otherwise: $\mathrm{P}_{\text {threshold }}=2 \times \mathrm{MAT}+14$ (last not observed on Canary Islands).

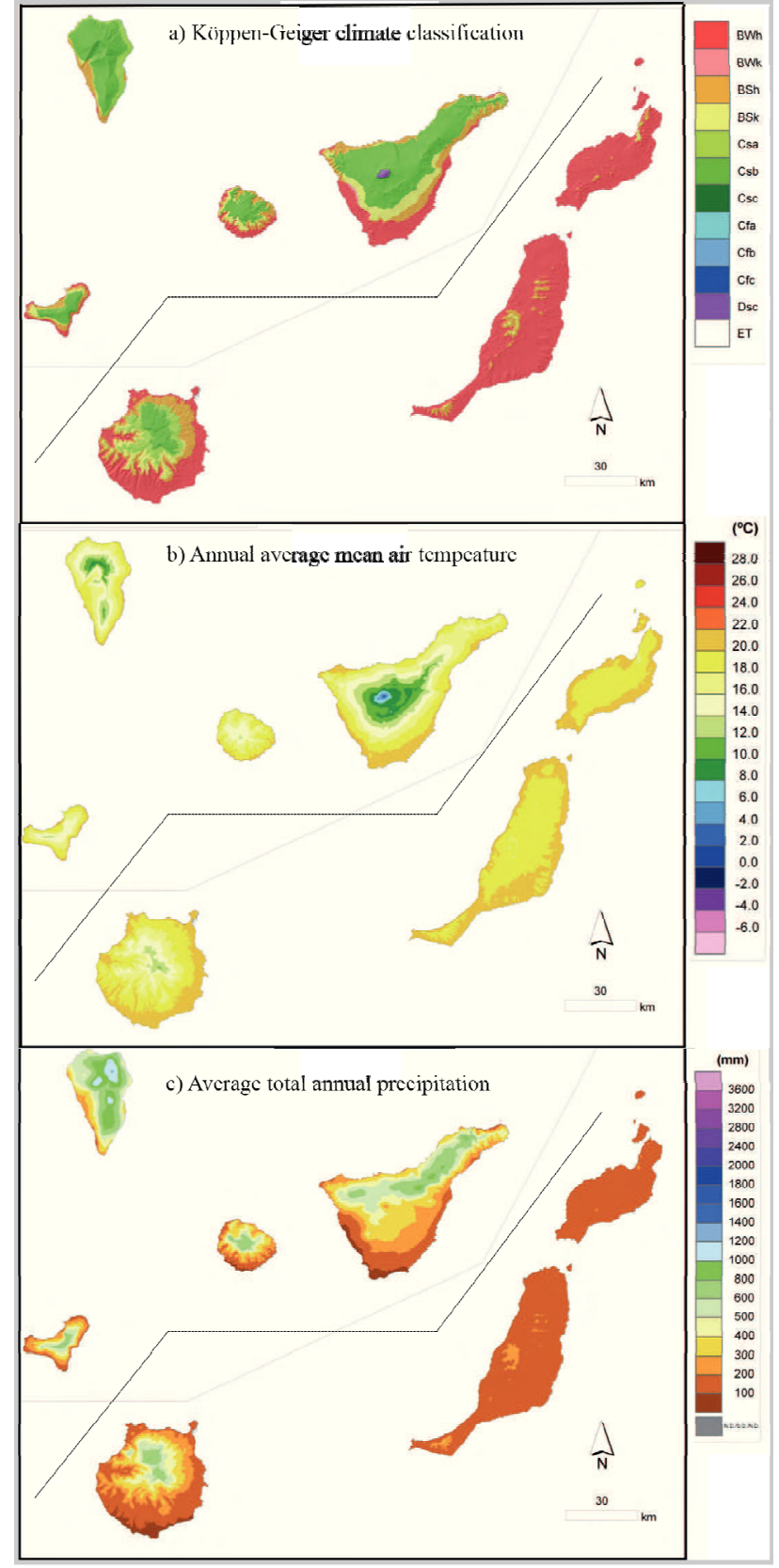

Figure 3. Climate of the Canary Islands from (AEMET, 2012); a) Köppen-Geiger Classification; b) Average annual temperature in ${ }^{\circ} \mathrm{C}$; c) average total annual precipitation in $\mathrm{mm}$. Islands were re-arranged for better fit on map.

Several studies have investigated the effects of climate change on the Canary Islands. Martín et al. (2012) studied the warming trend in Tenerife and found a statistically significant increase of $0.09 \pm 0.04 \mathrm{~K} /$ decade since 1944 . The night-time temperatures even increased by $0.17 \pm 0.04 \mathrm{~K}$ per decade, resulting in a decreasing diurnal cycle amplitude. The warming was faster in the high mountains than below the inversion layer between 600 and $1400 \mathrm{~m}$. Similarly, Luque et al. (2013) found significant warming trends of $0.09 \pm 0.05 \mathrm{~K}$ from 1946 and of $0.17 \pm 0.10 \mathrm{~K}$ from the 70ies for Gran Canaria. The increase was higher at night $(0.11 \pm 0.05 \mathrm{~K})$ than at day $(0.08 \pm 0.06 \mathrm{~K})$, so also here the diurnal temperature range decreased. The warming was faster in 
the mountains $(0.16 \pm 0.16 \mathrm{~K} /$ decade since the $70 \mathrm{ies})$ than at the coast (warming greater in leeward than windward sectors).

Of even more severe impact are the changes in precipitation, and the complex and steep topography makes the islands very sensitive to variations in the synoptic situation (García-Herrera et al., 2003). The precipitation in the Canary Islands showed a strong decreasing trend in the second half of the $20^{\text {th }}$ century, which is mostly due a decrease in simultaneous changes in the frequency and intensity of the strongest precipitation events (García-Herrera et al., 2003).

\section{RESULTS AND DISCUSSION}

In the following is it analyzed if important characteristics of the climate of the Canary Islands and its internal variation can be seen in the ACP.

\subsection{Surface temperature}

Figure 4 shows the MAST for all islands for 13:30 and 1:30 overpass time. At nighttime $(1: 30)$ the pattern is dominated by the topography and the vertical lapse rate. Further, anisotropic effects can be seen with the west-facing slopes being warmer. At daytime the pattern is much more differentiated with presumably a larger influence of the land cover. More specifically, the forested areas (especially on Tenerife, La Gomera, La Pama and El Hierro) are substantially cooler in the mean annual surface temperature then areas of same altitudes with less vegetation. Of course part of this effect could also be due to higher precipitation and soil moisture, which are closely related to the vegetation structure. Further some anisotropic effects of the irradiance can be seen as well. This becomes a bit clearer in the subset presented in Figure 5 with MAST at 10:30 and the warming until 13:30 for Mount Teide. While in the late morning the south-eastern orientated slopes are warmer, the temperature increased much more on the south and southwestern slopes until 13:30. Again, the effect of land cover and topography can be seen.

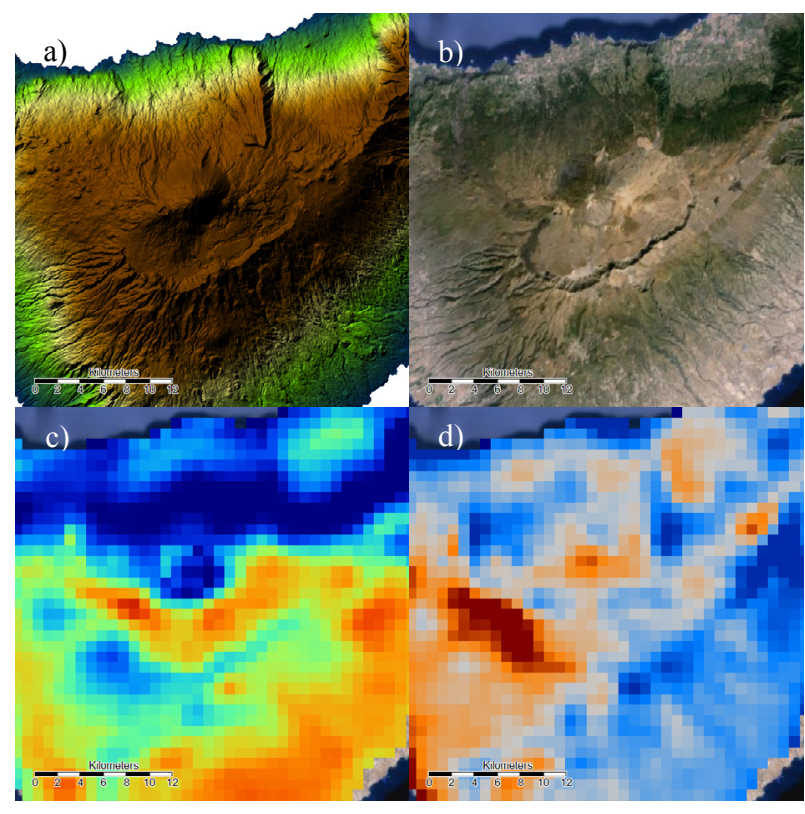

Figure 5. Tenerife subset with Mount Teide. a) SRTM DEM and analytical hill shading; b) Satellite image (Google Earth); c) Mean annual surface temperature (MAST) at 10:30; d) MAST difference between $10: 30$ and $13: 30$

Figure 6 shows the annual variation (YAST) in the surface temperature, which is generally low in this subtropical climate. The variation is smaller close to the sea, and increases with altitude, which is likely reflecting the high heat uptake in the ocean (more maritime climate) but possibly also the annual variation in the typical stratification as discussed before. The highest values $(>16 \mathrm{~K})$ are found at the north-eastern slopes of Mount Teide, which likely have most occurrence of snow during the course of year. As expected, the annual variation is much smaller and smother at night-time, while during daytime it again shows anisotropic effects with much smaller variation at the shaded northern slopes. However, this might also result from the fact that the border pixels are frequently not produced (see Figure 7).

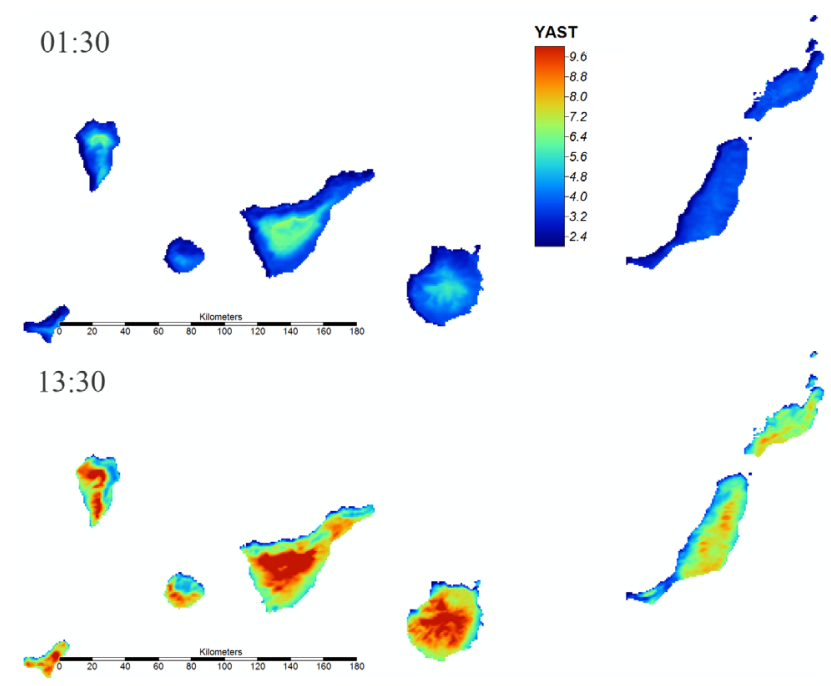

\footnotetext{
Figure 6. Yearly amplitude of surface temperature (YAST) in
$\mathrm{K}$ at 1:30 (upper) and 13:30 (lower) overpass time.

Figure 6. Yearly amplitude of surface temperature (YAST) in
$\mathrm{K}$ at 1:30 (upper) and 13:30 (lower) overpass time.
}

Figure 4. Mean annual surface temperature (MAST) in K at 13:30 (upper) and 1:30 (lower) overpass time. 


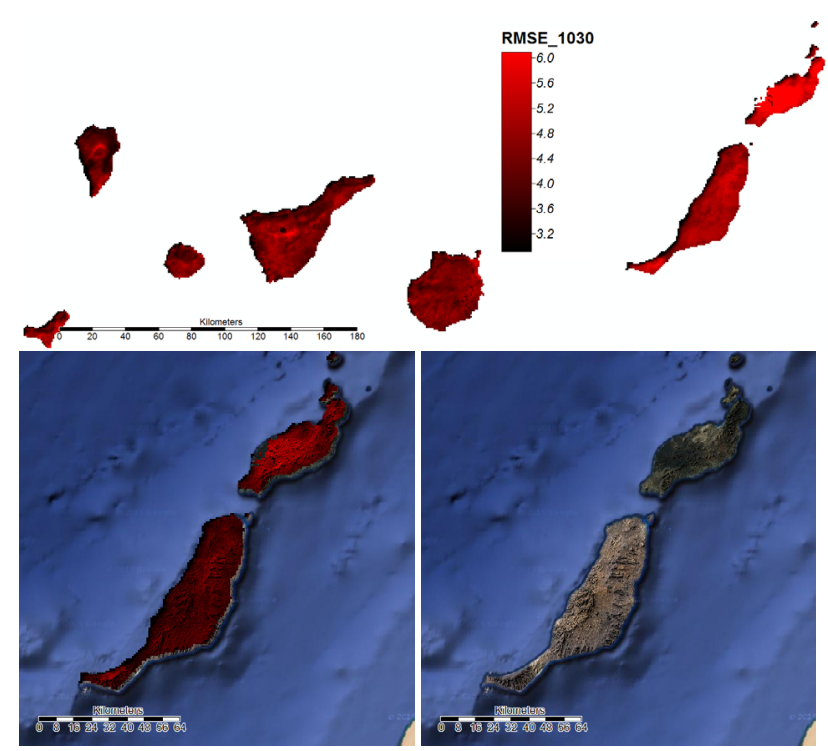

Figure 7. Root mean squared error (RMSE) in $\mathrm{K}$ at 10:30 = inter-diurnal and inter-annual variability of LST; Subset for arid islands; Base map (Google Earth, both with analytical hillshading)

Figure 7 shows the root mean squared error (RMSE) at 10:30 as measure of the inter-diurnal and inter-annual variability of surface temperature. The highest variations are found in the arid areas (especially congealed lava / igneous rocks on Fuerteventura) with high sensitivity towards solar irradiation due to the low albedo and high heat capacity as well as and high sensitivity of the sparse vegetation towards infrequent precipitation events.

\subsection{Frequency of cloud presence}

Figure 8 shows the number of cloud free acquisitions (meaning the numbers of days where the LST product was produced) for 13:30. Non-produced images occur for different reasons but clouds are by far the most likely one - for more detailed analysis the quality assessment flags could be consulted. Generally, the pattern follows the known cloud occurrence and stratification well. While the peaks of Tenerife and La Palma are almost entirely cloud free, the sea of clouds can very well be seen for Tenerife and La Palma for the areas below the inversion layer. For Gran Canaria, El Hierro, and La Gomera the cloud occurrence is much higher at the windward northern sectors. The arid eastern islands Fuerteventura and Lanzarote have little cloud occurrence but more than at Mount Teide. The cloud occurrence also matches the precipitation patterns in Figure 3 quite well. Even small variations such as the lower cloud occurrence in the El Golfo basin north of El Hierro are reproduced remarkably well. This results from the dissipation of clouds when downwelling the cliffs (see Figure 8a).
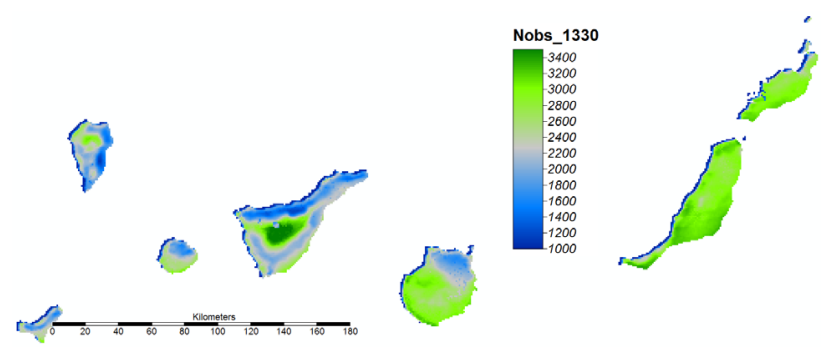

Figure 7. Number of cloud free observations at 13:30.

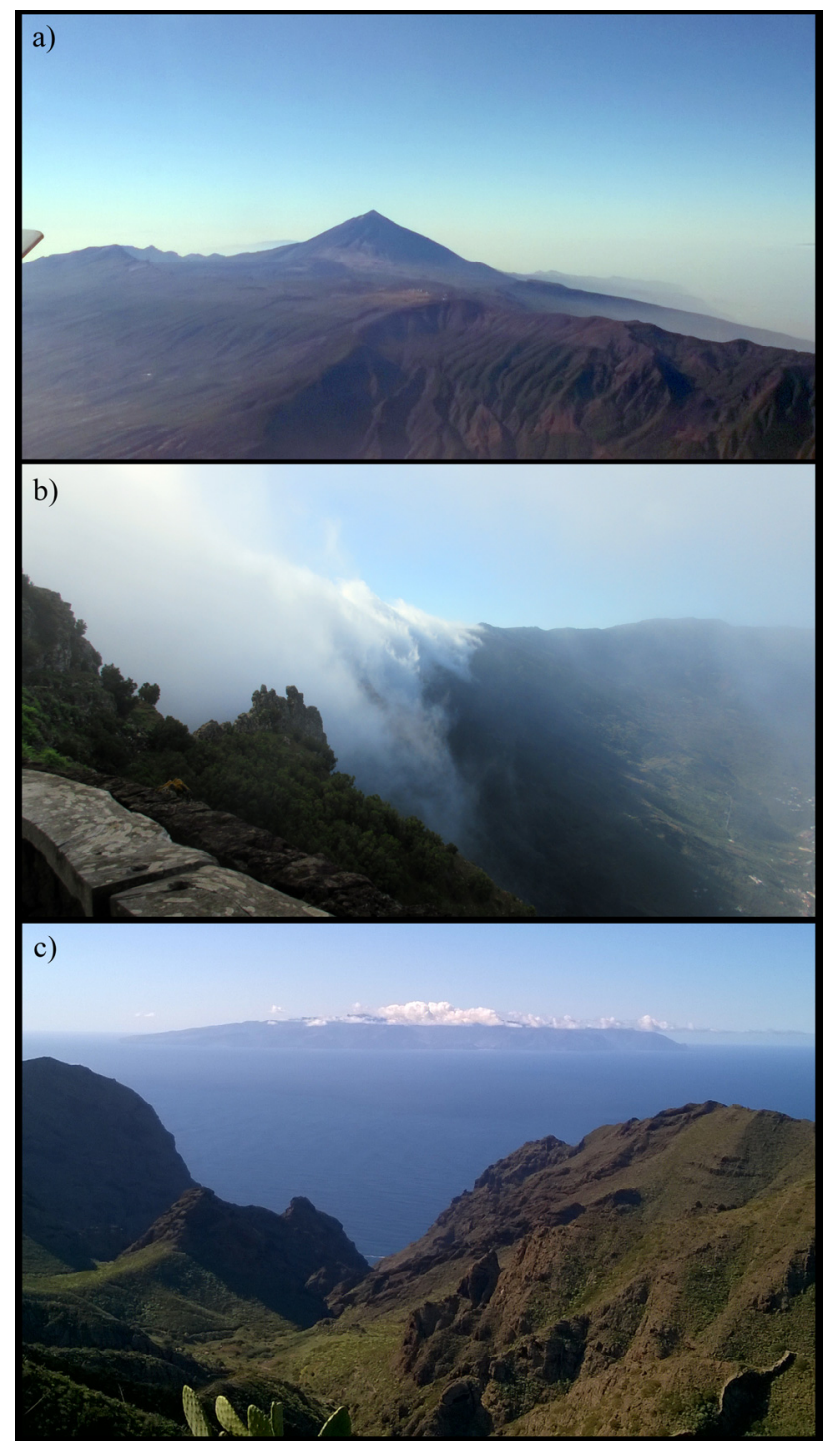

Figure 8. Typical cloud patterns on the Canary Islands. a) Mount Teide with clouds in the northern valleys of Teneriffe; b) Clouds dissolve when downwelling into the El Golfo basin on El Hierro: c) Sea of clouds around La Gomera seen from Tenerife; (C) Benjamin Bechtel, all rights reserved.

\subsection{Vertical stratification}

As already seen in the number of acquisitions, the stratification of the atmosphere can be diagnosed from the spatial pattern due to the complex and steep orography. Figure 9 shows MAST, YAST and the number of observations for 1:30 in $400 \mathrm{~m}$ height classes according to (Martín et al., 2012). It can be seen that the surface temperatures decrease constantly with an average lapse rate of about $4.5 \mathrm{~K} / \mathrm{km}$ (< dry adiabatic lapse rate) with a bit steeper gradient around $2000 \mathrm{~m}$. Although surface and air temperature are controlled by different processes and therefore not in equilibrium, they are directly related by the sensible heat flux and thus the lapse rate could indicate a stable atmospheric stratification of the nocturnal boundary layer. The nocturnal annual amplitude is increasing with height as noted previously, indicating a stronger maritime influence along the coast. Interestingly, above $2000 \mathrm{~m}$ the amplitude remains rather constant and the variation is small, which should be investigated further. The number of observations has a 
minimum between 800 and $1600 \mathrm{~m}$ and is constantly high above $2000 \mathrm{~m}$ which corresponds well with the typical stratification, and could indicate that the inversion is still present at night-times even if not seen in the surface temperatures. Below $1200 \mathrm{~m}$ the variation is very high, which might be differences between windward and leeward sectors. However, the cloud detection algorithm is presumably less reliable at night-time, since optical information is missing.
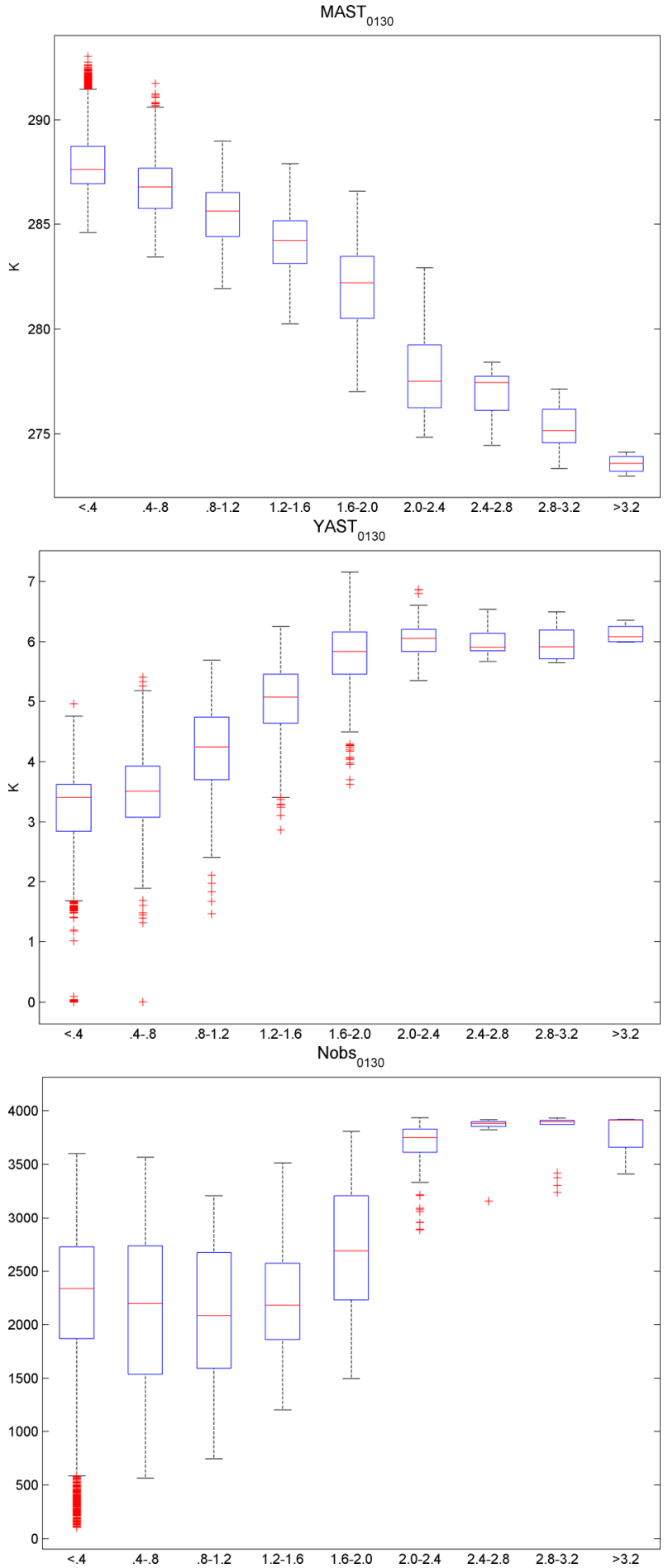

Figure 9. Distributions of mean annual surface temperature and yearly amplitude of surface temperature in $\mathrm{K}$ and number of observations at 1:30 by height in $\mathrm{km}$.
To investigate this further, MAST and observation numbers for all four acquisitions are shown in Figure 10 as a function of height (means are derived for $100 \mathrm{~m}$ intervals). MAST at 22:30 is very similar to MAST at 1:30 which suggests that the surface longwave outgoing radiation is fully compensated by the ground heat flux. The diurnal temperature range is slightly increasing above $2000 \mathrm{~m}$. During daytime MAST is decreasing at a comparable lapse rate between 500 to $1700 \mathrm{~m}$ but strongly increasing between $1900 \mathrm{~m}$ and $2500 \mathrm{~m}$. This temperature increase must be partly attributed to land cover (i.e. less vegetation), it may also be influenced by the atmospheric inversion even though it occurs at higher altitudes than those given by (Herrera et al., 2001). This assumption is also supported by the cloud distribution with a depression in the number of observations between $500 \mathrm{~m}$ and $1700 \mathrm{~m}$ (below the inversion) and a strong increase above this height. However, the cloud frequency might influence MAST, which - also considering clear sky conditions only - possibly contains more non detected clouds, previously shaded surfaces as well as reduced diffuse radiation in the lower areas. The change with altitude is stronger at nighttime, but the general pattern is similar for all observation times.
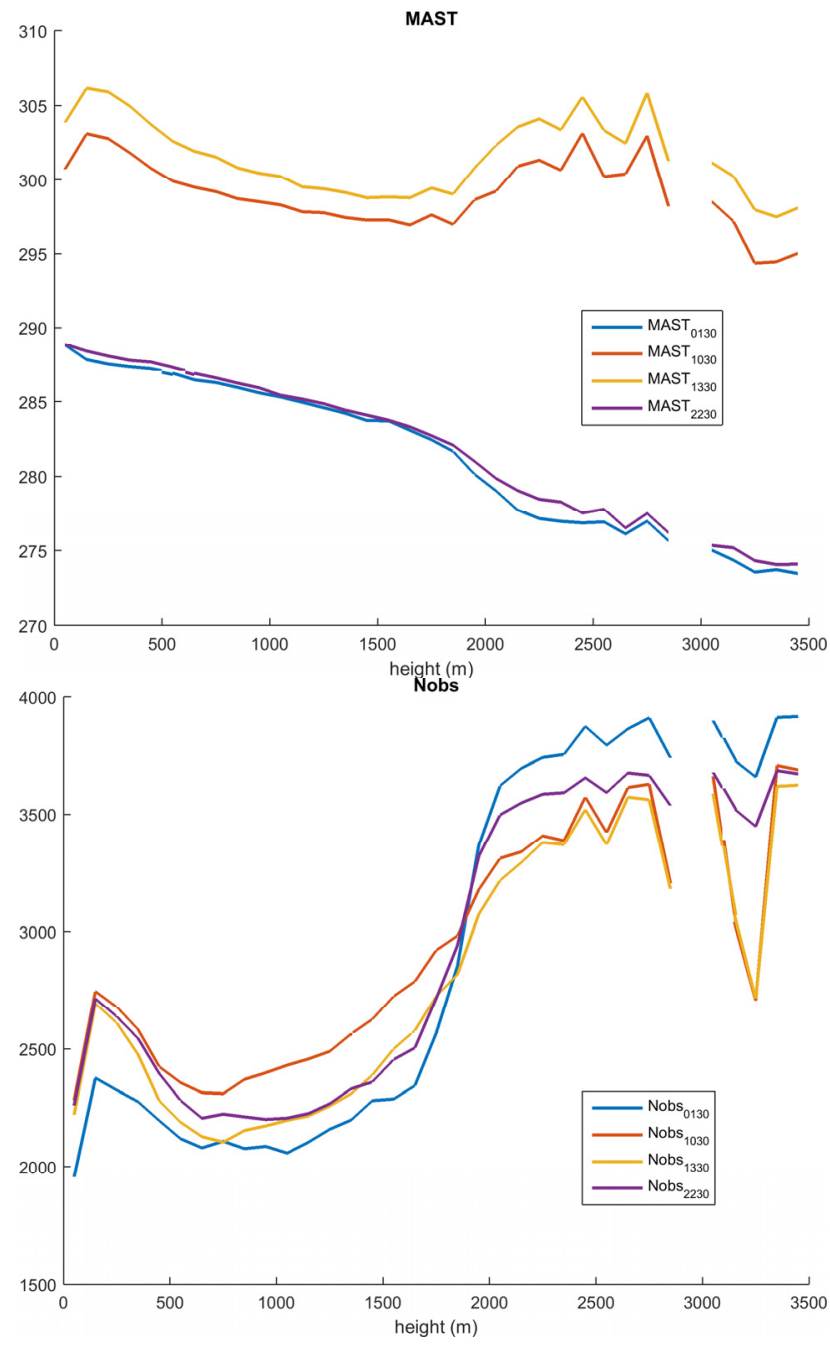

Figure 10. Mean annual surface temperature in K, and number of observations at different acquisition times and height levels (means of $100 \mathrm{~m}$ intervals). 
Interestingly there are substantially less clouds below the inversion layer at 10:30 than at 13:30 which means that convection is occurring in this period. The number of acquisitions has a local maximum around $200 \mathrm{~m}$ and drops close to the coast, which might have other reasons than clouds due to its anisotropic structure (see Figure 7). Since the cloud height is typically above ground height this is less meaningful than the strong gradient in the lower inversion layer.

\section{CONCLUSIONS AND OUTLOOK}

It was demonstrated that annual cycle parameters are a relevant source of climatic information at $\mathrm{km}$ scale and can be used to investigate the differentiation in complex orography. The Canary Islands with their diverse climates $(\mathrm{B}, \mathrm{C}$, and $\mathrm{D}$ climates in the Köppen classification) provided an ideal test case for this endeavour. Particularly, known features like the subsidence inversion, the resulting sea of clouds, the strong differentiation in precipitation between the flat and high islands and the northern and southern slopes at the latter could well be seen in the parameters. LST and the number of observations taken as proxies for air temperature and precipitation respectively demonstrate a remarkable resemblance with observations from the meteorological Atlas (AEMET, 2012), although it should be noted that both are interpolated from point data and therefore may contain spatial inaccuracies. Thus a more detailed comparison with stations data is needed and if this resemblance remains high, the ACP could well be used as covariates for spatial interpolation and statistical downscaling of observed data. The inversion found in surface temperature and suggested by the cloud height was higher than expected in annual average, but the relation between cloud occurrence, surface temperature and atmospheric stratification has to be studied in more detail. Future work will examine if the derived cloud height corresponds with stereographic methods (Merucci et al., 2016) and if the seasonal variation in the inversion layer height can be seen in LST time series. Further, it would be interesting to see if specific cloud patterns and heights can be attributed to precipitation events and if significant trends in cloud occurrence and surface temperature can be detected despite the relatively limited period of MODIS data availability. Eventually, possible applications such as Tourism could be investigated, since the warm and cloud-free areas in the ACP correspond very well with touristic centers on the respective islands.

\section{ACKNOWLEDGEMENTS}

I thank Paul Alexander and Klemen Zakšek for their valuable comments on the manuscript.

\section{REFERENCES}

AEMET, 2012. Climate atlas of the archipelagos of the Canary Islands, Madeira and the Azores. The Meteorological State Agency of Spain and the Institute of Meteorology, Portugal. www. meteo. pt/export/sites/default/bin/docs/tecnicos/Atlas Climatico_ilhas. pdf.

Bechtel, B., 2015. A New Global Climatology of Annual Land Surface Temperature. Remote Sens. 7, 2850-2870. doi:10.3390/rs 70302850

Bechtel, B., 2012. Robustness of Annual Cycle Parameters to Characterize the Urban Thermal Landscapes. Geosci. Remote Sens. Lett. IEEE 9, 876-880. doi:10.1109/LGRS.2012.2185034
Dorta-Antequera, P., Sánchez, C., Hernández-Brito, J.J., Mendoza-Rodríguez, S., Torres-Padrón, M.E., RodríguezSomoza, M.J., Siruela-Matos, V.F., et al., n.d. Sahara air incursions and dust deposition over the Canary Islands and its impact on the terrestrial and oceanic environment.

García-Herrera, R., Gallego, D., Hernández, E., Gimeno, L., Ribera, P., Calvo, N., 2003. Precipitation trends in the Canary Islands. Int. J. Climatol. 23, 235-241.

Herrera, R.G., Puyol, D.G., MartÍn, E.H., Presa, L.G., Rodríguez, P.R., 2001. Influence of the North Atlantic oscillation on the Canary Islands precipitation. J. Clim. 14, 3889-3903.

Luque, A., Martín, J.L., Dorta, P., Mayer, P., 2013. Temperature Trends on Gran Canaria (Canary Islands). An Example of Global Warming over the Subtropical Northeastern Atlantic. Atmospheric Clim. Sci. 2014.

Martín, J.L., Bethencourt, J., Cuevas-Agulló, E., 2012. Assessment of global warming on the island of Tenerife, Canary Islands (Spain). Trends in minimum, maximum and mean temperatures since 1944. Clim. Change 114, 343-355.

Marzol, M.V., 2008. Temporal characteristics and fog water collection during summer in Tenerife (Canary Islands, Spain). Atmospheric Res., Third International Conference on Fog, Fog Collection and DewFog and DewThird International Conference on Fog, Fog Collection and Dew 87, 352-361.

Merucci, L., Zakšek, K., Carboni, E., Corradini, S., 2016. Stereoscopic Estimation of Volcanic Ash Cloud-Top Height from Two Geostationary Satellites. Remote Sens. 8, 206. doi: $10.3390 /$ rs 8030206

NASA, 2015. The Shuttle Radar Topography Mission (SRTM) Collection User Guide lpdaac.usgs.gov/sites/default/ files/public/measures/docs/NASA_SRTM_V3.pdf

Peel, M.C., Finlayson, B.L., McMahon, T.A., 2007. Updated world map of the Köppen-Geiger climate classification. Hydrol Earth Syst Sci 11, 1633-1644. doi:10.5194/hess-11-1633-2007

Pérez, J.C., Díaz, J.P., González, A., Expósito, J., RiveraLópez, F., Taima, D., 2014. Evaluation of WRF parameterizations for dynamical downscaling in the Canary Islands. J. Clim. 27, 5611-5631.

Snyder, W.C., Wan, Z., Zhang, Y., Feng, Y.Z., 1998. Classification-based emissivity for land surface temperature measurement from space. Int. J. Remote Sens. 19, 2753-2774.

Wan, Z., 2008. New refinements and validation of the MODIS Land-Surface Temperature/Emissivity products 59-74.

Wan, Z., 2007. Collection-5 MODIS Land Surface Temperature Products Users' Guide. ICESS Univ. Calif. St. Barbara.

Wan, Z., Dozier, J., 1996. A generalized split-window algorithm for retrieving land-surface temperature from space. IEEE Trans. Geosci. Remote Sens. 34, 892-905. doi:10.1109/36.508406

Wan, Z., Zhang, Y., Zhang, Q., Li, Z.-L., 2004. Quality assessment and validation of the MODIS global land surface temperature. Int. J. Remote Sens. 25, 261-274. doi:10.1080/0143116031000116417 